\title{
1 Evaluation of early vigor traits in wild olive germplasm
}

2 L. León ${ }^{1 *}$, P. Díaz-Rueda ${ }^{3}$, A. Belaj ${ }^{1}$, R. De la Rosa ${ }^{1}$, C. Carrascosa ${ }^{2}$, J.M. Colmenero3 Flores $^{3 *}$

4

$5{ }^{1}$ Centro IFAPA “Alameda del Obispo”, Avda Menendez Pidal s/n 14004 Córdoba, Spain

$6 \quad{ }^{2}$ Viveros Sevilla, Ctra. Sevilla-Tocina km. 14.7, 41310 Brenes, Sevilla, Spain

$7 \quad{ }^{3}$ Instituto de Recursos Naturales y Agrobiología (IRNAS, CSIC), Av. Reina Mercedes 10

8 41012, Sevilla, Spain

9 *To whom correspondence should be addressed: L. León (lorenzo.leon@) 10 juntadeandalucia.es) and J.M. Colmenero-Flores (chemacf@irnase.csic.es)

\section{Abstract}

13 The control of the olive tree vigor is a critical factor to ensure adequate production and 14 longevity of high-density olive cultivation. To deal with this problem, we intend to take 15 advantage of the genetic variability present in the wild subspecies of Olea europaea to 16 identify genotypes of reduced vigor with optimal adaptability to diverse soils and adverse 17 environmental conditions. In this work, early vigor traits have been characterized in 18 different wild olive subspecies that could potentially be used as rootstocks to control the 19 vigor of grafted cultivars. Significant differences between genotypes were obtained for 20 all vigor traits and high values of broad sense heritability were obtained for most of them, 21 indicating strong genetic effect and therefore good possibilities for selection. Compared to 'Arbequina' and 'Picual' cultivars, some of the wild genotypes evaluated showed a

\section{Preprint submitted to Elsevier}


23 clear lower vigor at the end of the experimental period. These genotypes could be tested

24 as dwarfing rootstocks for high-density olive plantations.

25 Keywords: crop wild relatives; heritability; Olea europaea; rootstock; variability

\section{Introduction}

28 Crop wild relatives could represent interesting sources of variability for agronomic traits

29 difficult to find in cultivated materials, such as resistance to pest and diseases and abiotic

30 stresses, yield and quality traits. Thus, in the last years, the use of crop wild relatives

31 germplasm has been extensively promoted in breeding programs of several fruit trees and

32 nut crops (Aradhya et al., 2015).

33 Olea europaea subsp. europaea var. europaea and var. sylvestris constitute the botanical

34 varieties of cultivated and wild olives respectively, both of them widely spread 35 throughout the whole Mediterranean basin. Besides the subsp. europaea, five other 36 subspecies are included within the Olea europaea species, based on morphology and 37 geographical distribution, including subspp. cuspidata and laperrinei spread in tropical 38 and subtropical regions, subsp.guanchica, only recognized in the Canary Islands as well 39 as the only two polyploid subspp maroccana (6n) and cerasiformis (4n) present in south40 western Morocco; and Madeira archipelago, respectively (Green 2002; Besnard et al., $412013)$.

42 The potential use of olive wild genetic resources also known as oleasters as a source of 43 genetic variability for important agronomic traits has been suggested, particularly 44 regarding resistance to specific adverse biotic and abiotic environmental conditions 45 (Lavee and Zohary, 2011, Hernandez-Santana et al., 2019). Agronomic evaluation of 
46 progenies involving wild parents showed higher vigor, shorter juvenile period and more

47 abundant flowering than progenies from cultivated materials (Klepo et al., 2013).

48 Improved oil composition for some important quality components has been also reported

49 (Hannachi et al., 2009; León et al, 2018). However, wild olives also transmit undesirable

50 fruit traits to its descendants (particularly lower fruit size and oil content), which indicates

51 the need of additional back-cross generations and, therefore, slow down the selection

52 process (Klepo et al., 2014). The need for a longer selection period respect to the

53 cultivated germplasm has limited the potential use of wild relatives as parents in olive

54 breeding programs up to now.

55 Rootstock selection allows a straightforward way of valorizing wild genetic resources

56 (Warschefsky et al., 2016). In fact, grafting on wild materials was extensively used in the

57 antiquity as a propagation technique in olive. Thus, the analysis of ancient olive trees in several countries reveals that grafting by using seedling, pre-selected clonal rootstocks or oleasters has been a practice widely used in the Middle East (Barazani et al., 2014) and

60 at a lower extent in central (Lazović et al., 2016) and western part (Ninot et al., 2018) of

61 Mediterranean Basin.

62 However, it should be noted that olive trees are currently mainly grown on their own roots 63 and rootstocks are exceptionally used in olive compared to other fruit tree species. The 64 use of rootstocks has been recommended to cope with adverse biotic factors such as 65 soilborne disease (Porras-Soriano et al., 2003; Bubici and Cirulli, 2012) and abiotic 66 environmental conditions such as preventing frost injury (Panelli et al., 2002) or iron 67 chlorosis caused by Fe deficiency (Alcantara et al., 2003). The use of rootstocks to control 68 the vigor of the grafted cultivar has also been tested in several works (Baldoni and

69 Fontanazza, 1990; Panelli et al., 2002; Romero et al 2014; Rugini et al., 2016), 
70 particularly due to the spreading of high density hedgerows olive orchards in recent years and the need for increasing the number of cultivars suitable for this new growing system (Rallo et al., 2013).

The use of wild genetic resources as rootstocks may represent a new source of variability for important agronomic traits. In olive, it has been only studied as a way to improve resistance to Verticillium wilt of susceptible cultivars (Arias-Calderón et al., 2015; Jiménez-Fernández et al., 2016). However, to the best of our knowledge, a comprehensive evaluation of vigor traits in olive wild materials and the potential use of wild genetic resources as rootstocks for vigor control has not been attempted so far in olive.

The aim of this work was the characterization of early vigor traits in different wild olive subspecies representing a wide range of genetic variability of the species Olea europaea in order to study the variability and heritability for these traits and the relationships between them, and to identify genotypes that could be potentially used as rootstocks to optimize intensive olive cultivation.

\section{Materials and Methods}

86 Early vigor parameters were studied in 43 olive wild genotypes from different subspecies

87 and areas of origin:

88 - Olea europaea subsp. europaea var. sylvestris: 17 genotypes from open pollination of two trees coming from different provenances in Andalusia (11 from Cádiz (CAD) province (South-West of the region) and 6 from Jaén (JAE) province (East of the region)),

91 and 7 from open pollination of one tree of the area of Marrakech (MAR) in Morocco.

92 - Olea europaea subsp. guanchica (GUA): 9 genotypes from open pollination of one tree 93 of Canary Island 
94 - Olea europaea subsp. cuspidata (CUS): 1 genotype from open pollination of one tree 95 of South Africa

96 - Hybrids O. europaea sbsp. cuspidata x europeae var. sylvestris (CEH): 9 genotypes

97 from crosses.

98

99 Homogeneous plants of each genotype were initially obtained from in-vitro seedlings 100 germinated in 100\% strength Rugini medium (Rugini, 1984) without hormones. Uninodal 101 segments were further micropropagated in 100\% strength Rugini medium (Rugini, 1984)

102 supplemented with $1 \mathrm{mg} / \mathrm{l}$ zeatin. In vitro explants were incubated in a room chamber 103 under $16 \mathrm{~h}$ light photoperiod ( $34 \mu \mathrm{M}$ intensity with light-emitting diode (LED) $70 \%$ red 104 plus $30 \%$ blue) at $25 \pm 2{ }^{\circ} \mathrm{C}$. Explants were grown up to $7-8 \mathrm{~cm}$ height and transferred for 10521 days to rotting medium, consisting on 50\% strength Rugini medium supplemented 106 with $\alpha$-naphthalacetic acid $(0.8 \mathrm{mg} / 1)$. Rooted seedlings were acclimatized ex-vitro for

1073 weeks, transplanted to $1 \mathrm{~L}$ pots and grown under greenhouse conditions.

108 Afterwards plants were established in the field at the experimental farm of IFAPA Centre 109 "Alameda del Obispo" in Cordoba (Spain) in May 2015 at $4 \times 2 \mathrm{~m}$ spacing in a 110 randomized design with 6 replicates per genotype. Plants of 'Arbequina' and 'Picual' 111 cultivars obtained by standard vegetative propagation of semi-hardwood stem cutting 112 were included for comparison. Standard cultural practices were followed, with no pruning 113 to allow free development of plants and irrigation by in-line drip to avoid water stress of 114 plants.

115 Vigor traits measurements were taken in Summer (July) and Winter (January). In Summer 1162015 (S15) the following traits were measured: plant height $(\mathrm{PH})$, diameter of the main 117 axis at different heights (DG, DL, DC measured at ground level, $50 \mathrm{~cm}$ and $100 \mathrm{~cm}$ from 
118 ground, respectively), maximum internode length (IM), total number of nodes (NN) and

119 number of branches (NB), and length of the longest branch (BL). Plant height, diameter

120 of the main axis at different heights and length of the longest branch measurements were

121 repeated in Winter 2016 (W16), Summer 2016 (S16), Winter 2017 (W17) and Winter

1222018 (W18). Finally, canopy volume (CV) was also calculated in Winter 2018 from

123 measurements of canopy height and width for final categorization of plant vigor.

124 Descriptive statistics and variability box and whisker plots were obtained for the

125 evaluated agronomic traits. Analysis of variance was carried out to test differences

126 between genotypes and broad sense heritability was estimated as $h^{2}=\sigma_{G}^{2} /\left(\sigma_{G}^{2}+\sigma_{E}^{2}\right)$,

127 where $\sigma_{\mathrm{G}}^{2}$ is the variance between genotypes and $\sigma_{\mathrm{E}}^{2}$ is the residual variance. Spearman's

128 rank correlation between characters was calculated from average values per genotype.

\section{$130 \quad$ Results}

131 Overall, a wide variability was observed for all vigor traits measured at different time

132 points. This variability was maintained throughout the evaluation period for some of them

133 such as $\mathrm{PH}$, or gradually increased for others such as DG (Figure 1). Average PH

134 increased from $94 \mathrm{~cm}$ PH-S15 to $199 \mathrm{~cm} \mathrm{PH-W18,} \mathrm{while} \mathrm{DG} \mathrm{increased} \mathrm{from} 6 \mathrm{~mm}$ DG-

135 S15 to 39 mm TDG-W18.

136 

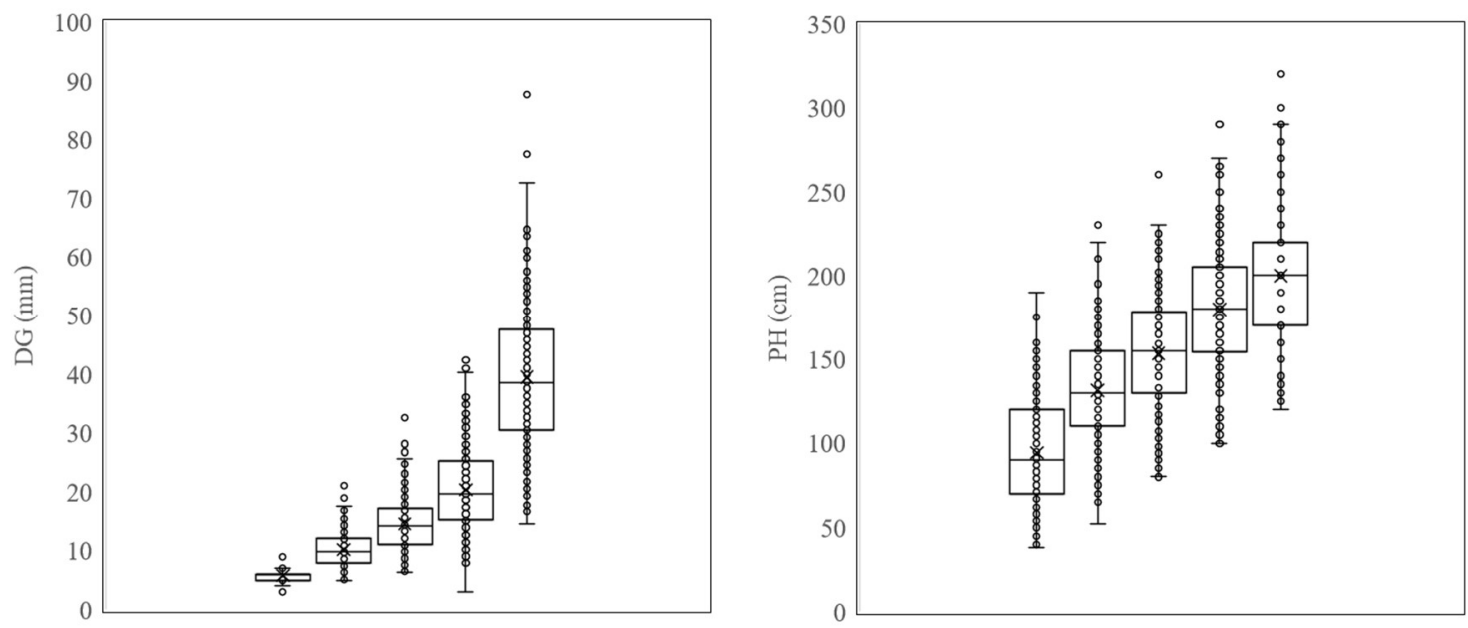

138 Figure 1.- Box and whisker plots for diameter of the main axis at ground level (DG) and plant height $(\mathrm{PH})$ measured sequentially during the evaluation period (from left to right:

140 Summer 2015, Winter 2016, Summer 2016, Winter 2017 and Winter 2018).

142 Significant differences between genotypes were obtained for all vigor traits, being the

143 variance component between genotypes higher than the error variance for most of them

144 (Table 1). As a consequence, high values of broad sense heritability were obtained for

145 most of the evaluated vigor traits. It should be noted that the highest heritability values

146 were obtained at the beginning of the evaluation period just after planting in the field, but

147 heritability values decreased throughout the evaluation period for those traits measured

148 sequentially due to a higher proportional increase of error variance as the plants grew

149 older. For instance, heritability values for PH decreased from 0.93 in S15 to a half 0.47

150 in W18. 
155 Table 1.- Variance components and heritability of vigor traits measured during the

156 evaluation period.

\begin{tabular}{|c|c|c|c|c|c|}
\hline & PH-S15 & PH-W16 & PH-S16 & PH-W17 & PH-W18 \\
\hline Genotype & 1017,05 & 697,88 & 649,20 & 764,21 & 762,25 \\
\hline Error & 72,39 & 255,47 & 404,22 & 571,94 & 846,73 \\
\hline \multirow[t]{2}{*}{$\mathrm{h} 2$} & 0,93 & 0,73 & 0,62 & 0,57 & 0,47 \\
\hline & BL-S15 & BL-W16 & BL-S16 & BL-W17 & \\
\hline Genotype & 58,73 & 214,85 & 278,26 & 356,11 & \\
\hline Error & 38,35 & 204,11 & 333,89 & 469,62 & \\
\hline \multirow[t]{2}{*}{ h2 } & 0,60 & 0,51 & 0,45 & 0,43 & \\
\hline & DG-S15 & DG-W16 & DG-S16 & DG-W17 & DG-W18 \\
\hline Genotype & 1,45 & 5,77 & 13,39 & 25,07 & 80,98 \\
\hline Error & 0,47 & 3,50 & 8,70 & 23,84 & 73,65 \\
\hline \multirow[t]{2}{*}{$\mathrm{h} 2$} & 0,75 & 0,62 & 0,61 & 0,51 & 0,52 \\
\hline & & DL-W16 & DL-S16 & DL-W17 & DL-W18 \\
\hline Genotype & & 4,30 & 7,72 & 16,92 & 44,58 \\
\hline Error & & 2,26 & 5,26 & 15,20 & 44,18 \\
\hline \multirow[t]{2}{*}{$\mathrm{h} 2$} & & 0,66 & 0,59 & 0,53 & 0,50 \\
\hline & & & DC-S16 & DC-W17 & DC-W18 \\
\hline Genotype & & & 7,56 & 13,70 & 43,04 \\
\hline Error & & & 4,59 & 11,92 & 46,48 \\
\hline h2 & & & 0,62 & 0,53 & 0,48 \\
\hline \multicolumn{6}{|c|}{ IM-S15 } \\
\hline Genotype & 76,90 & & & & \\
\hline Error & 36,34 & & & & \\
\hline \multirow[t]{2}{*}{ h2 } & 0,68 & & & & \\
\hline & NN-S15 & & & & \\
\hline Genotype & 113,04 & & & & \\
\hline Error & 20,46 & & & & \\
\hline \multirow[t]{2}{*}{ h2 } & 0,85 & & & & \\
\hline & NB-S15 & & & & \\
\hline Genotype & 99,88 & & & & \\
\hline Error & 40,85 & & & & \\
\hline h2 & 0,71 & & & & \\
\hline
\end{tabular}

Plant height $(\mathrm{PH})$, length of the longest branch (BL), diameter of the main axis at different heights (DG, DL, DC measured at ground level, $50 \mathrm{~cm}$ and $100 \mathrm{~cm}$ from ground, respectively), Maximum internode length (IM), total number of nodes (NN), number of branches (NB). Summer 2015 (S15), Winter 2016 (W16), Summer 2016 (S16), Winter 2017 (W17) and Winter 2018 (W18). 
162 Average data per genotype indicated also a high variability for vigor traits among 163 genotypes and a general reduction on the differences between genotypes as the plants

164 grew older (Table 2). As an example, coefficient of variation values for PH decreased 165 from $34.2 \%$ in S15 to $15.1 \%$ in W18. Only for diameter of the main axis measured at 166 ground level (DG) variability among genotypes remained similar during the evaluation 167 period, with coefficients of variation from 21.3 to $26.5 \%$. In any case, a general wide 168 variability and, therefore, possibilities for selection according to vigor characterization 169 could be inferred for all the evaluated traits and periods.

171 Table 2.- Mean, minimum, maximum and coefficient of variation for vigor traits (average

172 values per genotype) measured during the evaluation period on 43 wild genotypes.

\begin{tabular}{|c|c|c|c|c|c|}
\hline & PH-S15 & PH-W16 & PH-S16 & PH-W17 & PH-W18 \\
\hline Mean & 93,8 & 130,9 & 153,1 & 179,3 & 199,5 \\
\hline Min & 41,8 & 79,2 & 97,5 & 115,8 & 150,8 \\
\hline Max & 163,7 & 197,5 & 219,5 & 253,8 & 270,0 \\
\hline \multirow[t]{2}{*}{ CV (\%) } & 34,2 & 20,7 & 17,5 & 16,3 & 15,1 \\
\hline & BL-S15 & BL-W16 & BL-S16 & BL-W17 & \\
\hline Mean & 16,9 & 40,9 & 57,0 & 82,2 & \\
\hline Min & 4,5 & 13,8 & 19,7 & 28,6 & \\
\hline Max & 43,2 & 88,2 & 103,8 & 117,8 & \\
\hline \multirow[t]{2}{*}{ CV (\%) } & 47,6 & 38,8 & 32,6 & 25,5 & \\
\hline & DG-S15 & DG-W16 & DG-S16 & DG-W17 & DG-W18 \\
\hline Mean & 5,8 & 10,2 & 14,5 & 20,3 & 39,4 \\
\hline Min & 3,5 & 5,9 & 8,1 & 9,9 & 18,7 \\
\hline Max & 9,2 & 16,6 & 25,9 & 37,4 & 67,6 \\
\hline \multirow[t]{2}{*}{ CV (\%) } & 21,3 & 24,8 & 26,5 & 26,5 & 24,5 \\
\hline & & DL-W16 & DL-S16 & DL-W17 & DL-W18 \\
\hline Mean & & 7,3 & 10,4 & 15,1 & 30,1 \\
\hline Min & & 3,4 & 4,6 & 7,1 & 15,5 \\
\hline Max & & 11,5 & 16,6 & 26,5 & 44,6 \\
\hline \multirow[t]{2}{*}{ CV (\%) } & & 29,7 & 28,3 & 29,2 & 23,8 \\
\hline & & & DC-S16 & DC-W17 & DC-W18 \\
\hline Mean & & & 6,4 & 9,5 & 22,6 \\
\hline Min & & & 1,3 & 2,3 & 8,4 \\
\hline
\end{tabular}




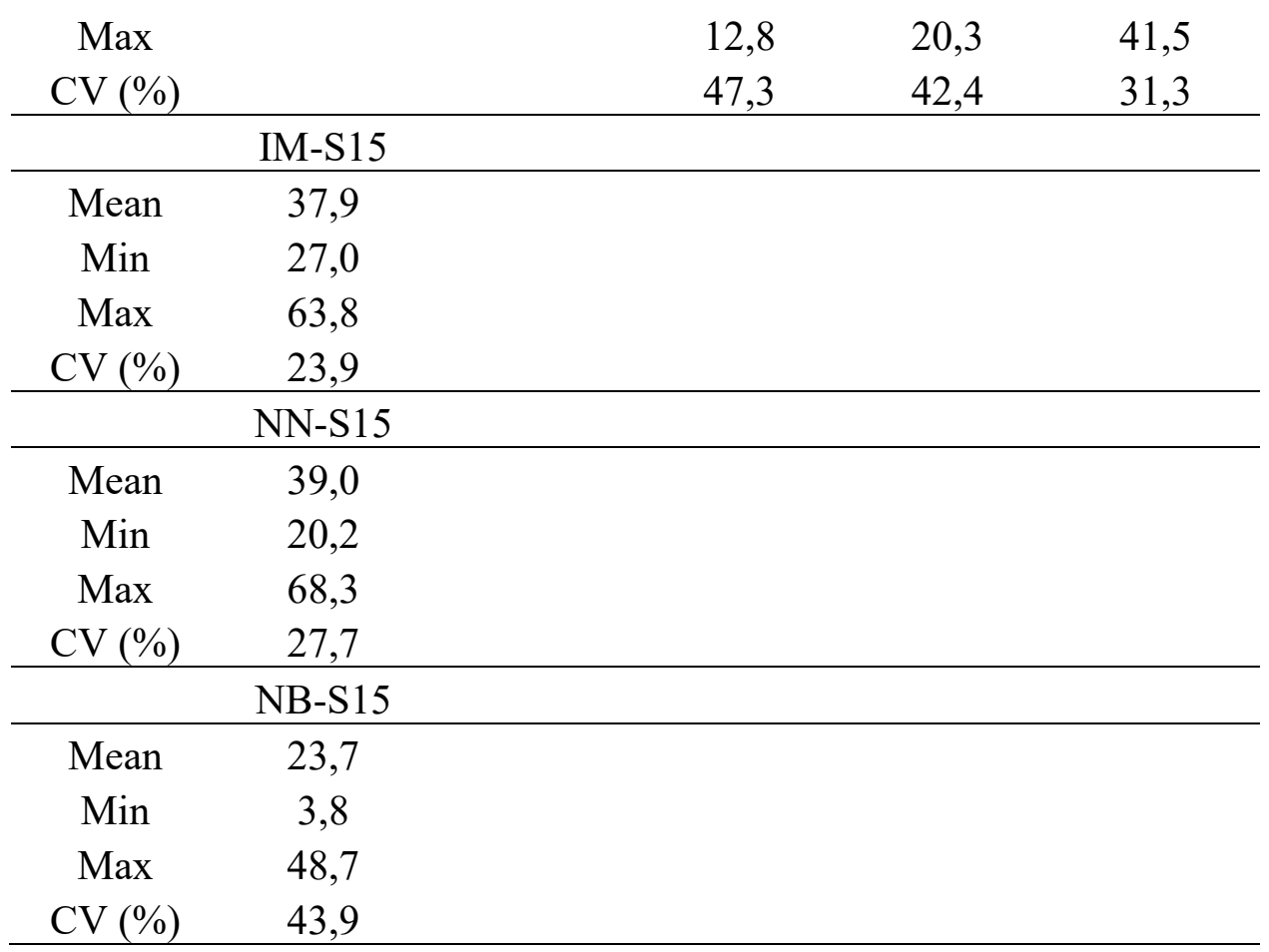

Plant height (PH), length of the longest branch (BL), diameter of the main axis at different heights (DG, length (IM), total number of nodes (NN), number of branches (NB). Summer 2015 (S15), Winter 2016

176 (W16), Summer 2016 (S16), Winter 2017 (W17) and Winter 2018 (W18).

178 Spearman's rank analysis showed significant correlations among the different vigor parameters (Figure 2). In general, correlation values were higher between different vigor traits measured at the same timepoint or between common vigor traits measured at

181 consecutive timepoints. However, some traits such as NB-S15 and PH-W18 showed

182 always slight correlations with the other evaluated vigor parameters $(r<0.60)$. Canopy

183 volume (CV), calculated in Winter 2018 showed significant correlation with all the 184 evaluated vigor traits, the highest values $(>0.80)$ been observed with traits measured from

185 Summer 2016, i.e. one year after planting in field. Among them, CV showed the highest 186 correlation with diameter of the main axis measured at $50 \mathrm{~cm}$ from ground in Winter 2018 187 (DL-W18, r=0.901). 


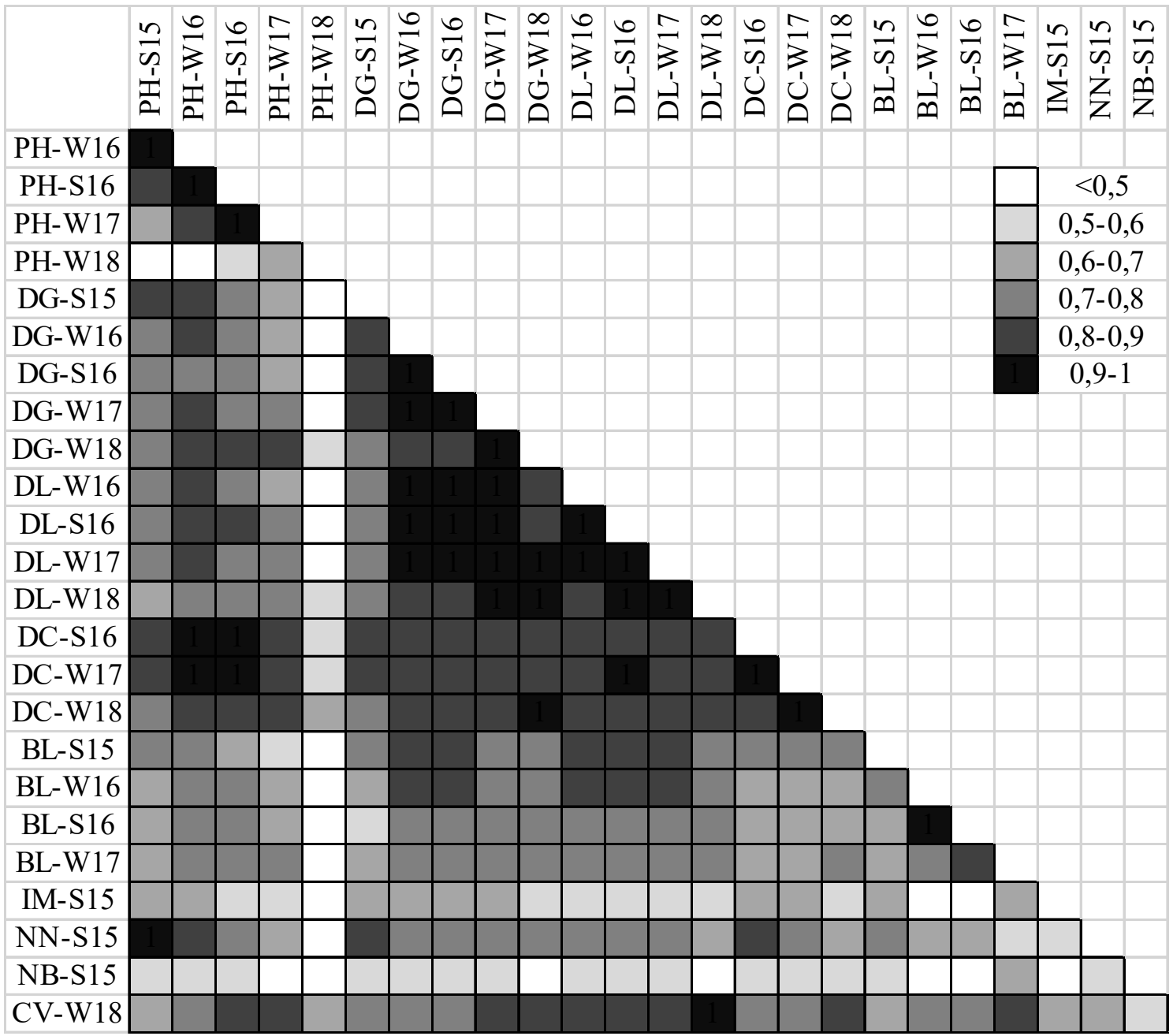

190 Figure 2.- Spearman's rank correlations between average vigor traits per genotype

191 measured during the evaluation period. Plant height $(\mathrm{PH})$, length of the longest branch (BL),

192 diameter of the main axis at different heights (TDG, TDL, TDC measured at ground level, $50 \mathrm{~cm}$ and 100 $\mathrm{cm}$ from ground, respectively), Maximum internode length (IM), total number of nodes (NN), number of branches (NB). Summer 2015 (S15), Winter 2016 (W16), Summer 2016 (S16), Winter 2017 (W17) and Winter 2018 (W18)

197 Final classification of genotypes according to values on CV-W18 and TDL-W18 showed lowest vigor was obtained in sylvestris genotypes from Jaen (Spain) and Marrakech (Morocco) provenances, while the highest vigor was obtained in sylvestris genotypes

201 from Cadiz (Spain) and genotypes from crosses cuspidata x sylvestris. However, a wide variability was obtained in all cases, particularly in genotypes from guanchica origin. 
some of the wild genotypes evaluated showed a clear lower vigor at the end of the experimental period.

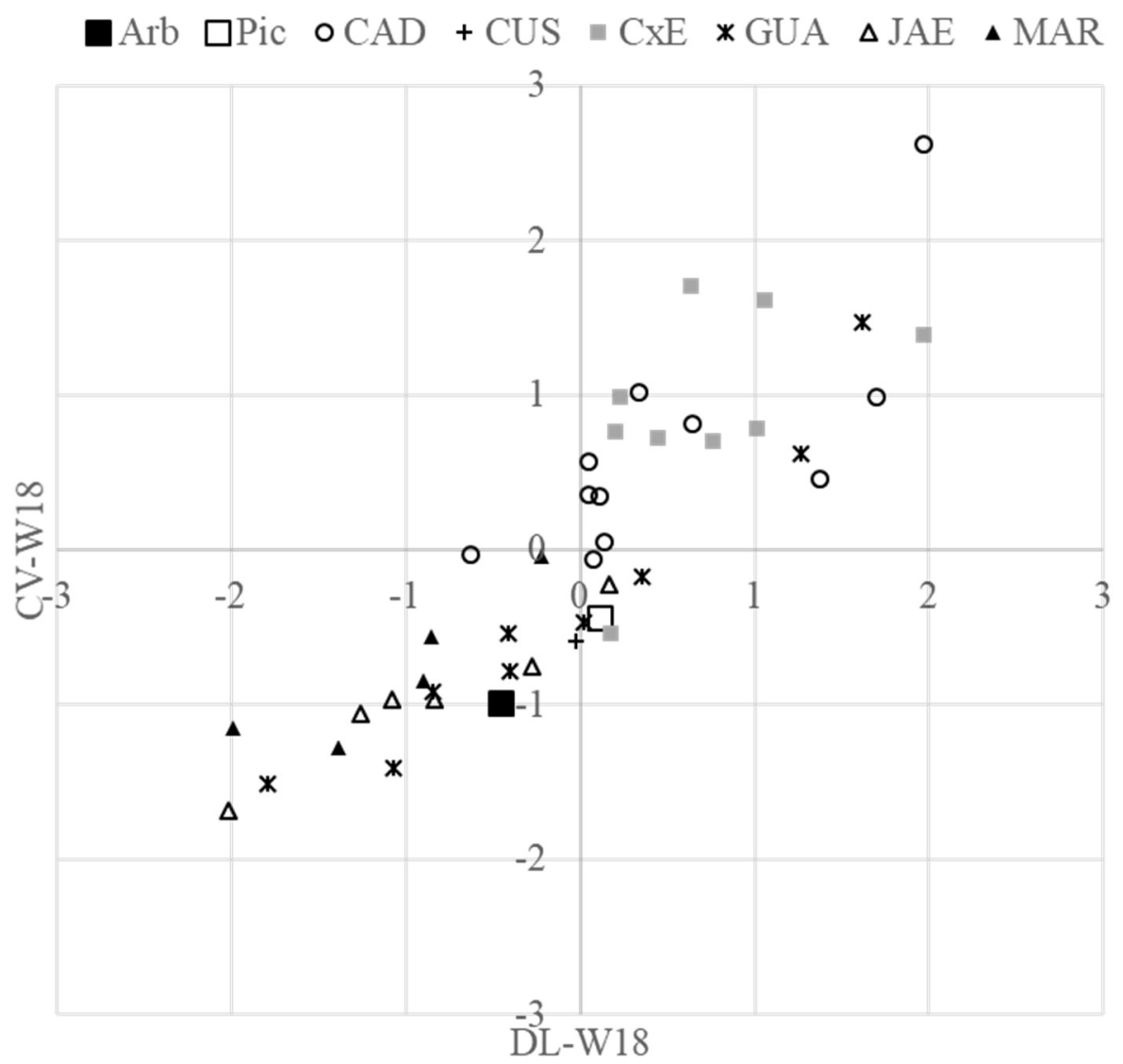

208 Figure 3.- Scatter plot of average data per genotype for diameter of the main axis at 50

$209 \mathrm{~cm}$ from ground and canopy volume measured at the end of the experimental period in

210 Winter 2018, TDL-W18 and CV-W18, respectively. Data are grouped according to the

211 origin of the genotypes, including 'Arbequina' and 'Picual' as controls for comparison.

212 Data were normalized by the mean and SD for each trait.

\section{Discussion}

215 High density hedgerows olive orchards have spread in the last decades in many olive 216 producing countries taking advantages of the higher initial productivity and the 
217 possibilities for labor mechanization, particularly continuous harvesting by straddle

218 harvesting machines (Rallo et al., 2013). However, the difficulties for canopy size control

219 allowing adequate long-term management of plantations mean that only a very limited

220 number of cultivars have been successfully adapted for this system, contrarily to

221 traditional olive growing in which large number of cultivars are available for cultivation.

222 Therefore, only a few early-bearing, highly productive, low vigor and weeping habit cultivars such as 'Arbequina' and 'Arbosana' are widely planted in hedgerow systems

224 (De la Rosa et al., 2007).

225 Among the potential techniques to control the vigor of fruit trees, the use of dwarfing 226 rootstocks has been widely used in many fruit species (Gregory et al., 2013). It is well

227 known that full range of tree size control, from dwarfing to highly vigorous, could be 228 achieved in several fruit tree species, particularly apple, by using adequate rootstocks, which allows design of specific growing systems and planting density in each case

230 (Cummins and Aldwinckle,1983). In olive, the use of rootstocks as a vigor control tool

231 has been attempted in several works by using different plant materials including cultivars

232 and breeding selections obtained by classical cross-breeding or mutagenesis (Baldoni and

233 Fontanazza, 1990; Romero et al 2014; Rugini et al., 2016).

234 A wide intraspecific variability for vigor traits has been reported from the evaluation in 235 cultivar collections (Del Río et al., 2005; Tous et al., 2005). A quite similar variability 236 has been found in this work in genotypes from different subspecies and area of origin. 237 Thus, for instance, a coefficient of variation of $24.8 \%$ was obtained from the analysis of 238 trunk diameter ten years after planting in 61 cultivars evaluated at the World Olive 239 Germplasm of IFAPA in Córdoba compared to $24.5 \%$ obtained in 43 olive wild 240 genotypes in this work. A high heritability and strong genetic effect could be also inferred 
241 from the evaluation of vigor traits in these cultivar collections. However, significant

242 environmental influence has also been observed for some cultivars, which underlined the

243 need of extensive testing in different environments for adequate selection. In fact, a high

244 correlation has been reported between olive tree vigor and different soil and landscape

245 characteristics such as thickness of the root zone, clay and cation exchange capacity and

246 distance to summit (Gálvez et al., 2004).

247 The whole results of vigor evaluation should be considered in terms of variability,

248 heritability and correlation among them. A high correlation between 17 different vigor

249 parameters was also observed in the characterization of olive progenies from crosses

250 between different cultivars, which allows the selection of a group of them as the best

251 growth descriptors based on their influence by parent genotype (Hammami et al., 2011).

252 Moreover, a high influence of plant age on growth habit traits was also determined and

253 early characterization at the time of planting in the field was suggested the most

254 appropriate age for evaluating seedling growth parameters (Hammami et al., 2011). Early

255 vigor measurements at the seedling stage before planting in the field was also proposed

256 in olive progenies as a tool for selection for short juvenile period (De la Rosa et al., 2006).

257 In this work however, measurements taken early after planting showed high heritability

258 and variability among genotypes, but lower correlation with final characterization of the

259 genotypes. The results obtained suggest that measurements taken from one year after

260 planting could be considered more efficient for selection.

261 Among the wild genotypes evaluated in this work, some of them showed a clear lower

262 vigor than 'Arbequina' at the end of the experimental period and could be considered

263 potentially interesting dwarfing rootstocks. Future works should be carried out to test

264 whether the differential vigor in the evaluated wild materials is extensible to the grafted 
265 cultivars of interest. Previous works testing single cultivars grafted on a range of potential 266 interesting rootstocks indicate that the intrinsic vigor of some rootstock is transferred to

267 the grafted cultivar. However, opposite results were also found in some cases, although it 268 should be noted that explicit evaluation of vigor of the rootstock used was not carried out 269 but based on previous literature (Troncoso et al., 1990; Romero et al., 2014). Similarly, 270 different vigor control ability has been obtained for some rootstocks depending on the 271 cultivar grafted, while a general dwarfing effect was observed for some others (Panelli et 272 al., 2002). These partly contradictory results suggest that further research is still necessary 273 to guarantee adequate choice of rootstocks. Again, the environmental conditions should 274 be also carefully considered in testing. For instance, water availability showed a marked 275 effect on growth and production parameters that obscure the potential rootstock effect in experiments with reciprocal scion/rootstock combination of three olive cultivars (Lavee and Schachtel, 1999; Hernandez-Santana et al., 2019). Moreover, the effect of grafting itself has been showed to control vigor by reducing plant size of self-grafted genotypes

279 (Rugini et al., 2016), although no effect of self-grafting has also been reported for some 280 cultivars (Panelli et al., 2002).

281 Several mechanisms have been suggested as responsible of the dwarfing potential of olive rootstock, mainly related to the hydraulic architecture of the different scion/rootstock combinations (Nardini et al., 2006), as also reported for other fruit tree species (Cohen et

284 al., 2007). The hydraulic characterization of the wild plant materials showing contrasting 285 dwarf effect in our work could provide valuable information in future. 


\section{Conclusions}

290 A wide variability for early vigor traits has been obtained from the evaluation of wild

291 olive germplasms from different origins. In particular, low vigor and potentially

292 interesting dwarfing effect was obtained in some sylvestris genotypes from Jaen (Spain)

293 and Marrakech (Morocco) provenances and some genotypes from guanchica origin.

294 Future works should be carried out to test whether the differences in growth traits between

295 the studied plant materials are translated into vigor control of grafted materials and,

296 moreover, whether it represents a general effect or it is limited to particular

297 scion/rootstock combinations. Moreover, the potential effect of the rootstock on other

298 important agronomic traits of the grafted cultivar, such as earliness of bearing,

299 productivity fruit and oil traits, should be also evaluated to guarantee adequate choice of

300 rootstock. The use of rootstocks as a tool to control vigor in olive could open new

301 possibilities for future olive growing, mainly regarding high-density hedgerows olive

302 orchards where only a very limited number of cultivars have been successfully adapted

303 up to now.

\section{Acknowledgements}

306 This work was supported by the FEDER/CSIC grant "RECUPERA-2020" (Ref.

307 20134R089), the Spanish National Research Council grants CSIC-201640E069 and

308 CSIC-201740E041, and the contract agreement between IFAPA and Viveros Sevilla

309 (CAICEM15-02). Technical assistance of Francisco Durán and Miriam Pérez-Sayago is

310 acknowledged. 


\section{References}

314 Alcántara, E., Cordeiro, A.M., Barranco, D., 2003. Selection of olive varieties for

315 tolerance to iron chlorosis. Journal of Plant Physiology 160, 1467-1472.

316 Aradhya, M.K., Preece, J., Kluepfel, D.A., 2015. Genetic Conservation, Characterization

317 and Utilization of Wild Relatives of Fruit and Nut Crops at the USDA Germplasm

318 Repository in Davis, California. Acta Hort 1074, 95-104.

319 Arias-Calderón, R., Rodríguez-Jurado, D., Leon, L., Bejarano-Alcázar, J., De la Rosa, R., 320 Belaj, A., 2015. Pre-breeding for resistance to Verticillium wilt in olive: Fishing in the 321 wild relative gene pool. Crop Protection 75, 25-33.

322 Baldoni, L., Fontanazza, G., 1990. Preliminary-results on olive clonal rootstocks behavior 323 in the field. Acta Horticulturae 286, 37-40.

324 Barazani, O., Westberg, E., Hanin, N., Dag, A., Kerem, Z., Tugendhaft, Y., Hmidat, M., 325 Hijawi, T., Kadereit, J.W., 2014. A comparative analysis of genetic variation in rootstocks 326 and scions of old olive trees - a window into the history of olive cultivation practices and 327 past genetic variation. BMC Plant Biol 14, 146.

328 Besnard, G., Khadari, B., Navascués, M., Fernández-Mazuecos, M., El Bakkali, A., 329 Arrigo, N., Baali-Cherif, D., de Caraffa, V.B., Santoni, S., Vargas, P., Savolainen, V., 330 2013. The complex history of the olive tree: from Late Quaternary diversification of

331 Mediterranean lineages to primary domestication in the northern Levant. P Roy Soc Lond 332 B Bio 280, 1756.

333 Bubici, G., and Cirulli, M., 2012. Control of Verticillium wilt of olive by resistant 334 rootstocks. Plant Soil 352, 363-376. 
335 Cohen, S., Naor, A., Bennink, J., Grava, A., Tyree, M., 2007. Hydraulic resistance com336 ponents of mature apple trees on rootstocks of different vigours. J Exp Bot 58, 4213-4224.

337 Cummins, J.N.; Aldwinckle, H.S., 1983. Rootstock Breeding. In: J.N. Moore, and J. 338 Janick (eds.), Methods in Fruit Breeding, 294-327. Purdue University Press, West 339 Lafayette, Indiana.

340 De la Rosa, R., Kiran, A.I., Barranco, D., León, L., 2006. Seedling vigour as a 341 preselection criterion for short juvenile period in olive breeding. Aust J Agr Res 57, 477342481.

343 De la Rosa, R., León, L., Guerrero, N., Rallo, L., Barranco, D., 2007. Preliminary results 344 of an olive cultivar trial at high density. Aust J Agr Res 58, 392-395.

345 Del Río, C., Caballero, J.M., García-Fernández, M.D., 2005. Vigor. Banco de 346 Germoplasma de Córdoba. En: Variedades de olivo en España (Libro II: Variabilidad y 347 selec- ción). Rallo, L., Barranco, D., Caballero, J.M., Del Río, C., Martín, A., Tous, J., 348 Trujillo, I. (Eds.). Junta de Andalucía, M.A.P.A. y Ediciones Mundi-Prensa. Madrid.

349 Galvez, M., Parra, M.A., Navarro, C., 2004. Relating tree vigour to the soil and landscape 350 characteristics of an olive orchard in a marly area of southern Spain. Sci Hort 101, 291351303.

352 Green, P.S., 2002. A revision of Olea L. (Oleaceae). Kew Bull 57, 91-140.

353 Gregory, P.J., Atkinson, C.J., Bengough, A.G., Else, M.A., Fernandez-Fernandez, F., 354 Harrison, R.J., Schmidt, S., 2013. Contributions of roots and rootstocks to sustainable, 355 intensified crop production. J Exp Bot 64, 1209-1222.

356 Hammami, S.B.M., Leon, L., Rapoport, H.F., De la Rosa, R., 2011. Early growth habit 357 and vigour parameters in olive seedlings. Sci Hort 129, 761-768. 
358 Hannachi, H., Sommerlatte, H., Breton, C., Msallem, M., El Gazzah, M., Ben El Hadj, S.,

359 Berville, A., 2009. Oleaster (var. sylvestris) and subsp cuspidata are suitable genetic

360 resources for improvement of the olive (Olea europaea subsp europaea var. europaea).

361 Genet Resour Crop Evol 56, 393-403.

362 Hernandez-Santana, V., Diaz-Rueda, P., Diaz-Espejo, A., Raya-Sereno, M. D., Gutierrez-

363 Gordillo, S., Montero, A., Perez-Martin, A., Colmenero-Flores, J. M., and Rodriguez-

364 Dominguez, C. M. (2019). Hydraulic Traits Emerge as Relevant Determinants of Growth

365 Patterns in Wild Olive Genotypes Under Water Stress. Front Plant Sci 10, 291.

366 Jimenez-Fernandez, D., Trapero-Casas, J.L., Landa, B.B., Navas-Cortes, J.A., Bubici, G.,

367 Cirulli, M., Jimenez-Diaz, R.M., 2016. Characterization of resistance against the olive-

368 defoliating Verticillium dahliae pathotype in selected clones of wild olive. Plant Path 65, 369 1279-1291.

370 Klepo, T., De la Rosa, R., Satovic, Z., Leon, L., Belaj, A., 2013. Utility of wild germplasm 371 in olive breeding. Sci Hort 152, 92-101.

372 Klepo, T., Toumi, A., de la Rosa, R., Leon, L., Belaj, A., 2014. Agronomic evaluation of 373 seedlings from crosses between the main Spanish olive cultivar 'Picual' and two wild olive 374 trees. J Hortic Sci Biotech 89, 508-512.

375 Lazović, B., Adakalić, M., Pucci, C., Perović, T., Bandelj, D., Belaj, A., Mariotti, R., 376 Baldoni, L., 2016. Characterizing ancient and local olive germplasm from Montenegro. 377 Sci Hort 209, 117-123.

378 Lavee, S., Zohary, D., 2011. The potential of genetic diversity and the effect of 379 geographically isolated resources in olive breeding. Isr J Plant Sci 59, 3-13. 
Lavee, S., Schachtel, J., 1999. Interaction of cultivar rootstock and water availability on

381 olive tree performance and fruit production. Acta Hort 474, 399-401.

382 León, L., de la Rosa, R., Velasco, L., Belaj, A., 2018. Using Wild Olives in Breeding

383 Programs: Implications on Oil Quality Composition. Front Plant Sci 9, 232.

384 Nardini, A., Gasco, A., Raimondo, F., Gortan, E., Lo Gullo, M.A., Caruso, T., Salleo, S., 385 2006. Is rootstock-induced dwarfing in olive an effect of reduced plant hydraulic 386 efficiency? Tree Physiol 26, 1137-1144.

387 Ninot, A., Howad, W., Aranzana, M.J., Senar, R., Romero, A., Mariotti, R., Baldoni, L., 388 Belaj, A., 2018. Survey of over 4,500 monumental olive trees preserved on-farm in the 389 northeast Iberian Peninsula, their genotyping and characterization. Sci. Hortic. 231, 253390264.

391 Pannelli, G., Rosati, S., Rugini, E., 2002 The Effect of Clonal Rootstocks on Frost

392 Tolerance and on Some Aspects of Plant Behaviour in Moraiolo and S. Felice Olive 393 Cultivars Acta Hort 586, 247-250.

394 Porras-Soriano, A., Soriano-Martín, M.L., Porras-Piedra, A., 2003. Grafting olive cv. 395 Cornicabra on rootstocks tolerant to Verticillium dahliae reduces their susceptibility. 396 Crop Prot 22, 369-374.

397 Rallo, L., Barranco, D., Castro-García, S., Connor, D.J., Gómez del Campo, M., Rallo, 398 P., 2013. High-Density Olive Plantations. Hortic Rev 41, 303-383.

399 Romero, A., Hermoso, J.F., Tous, J., 2014. Olive Rootstocks to Control 'Arbequina 400 IRTA-I18' Clone Vigour Results from a Second One Comparative Trial. Acta Hort 1057, $401 \quad 577-584$. 
402 Rugini, E., 1984. In vitro-propagation of some olive (Olea europaea sativa L.) cultivars 403 with different root-ability, and medium development using analytical data from 404 developing shoots and embryos. Sci Hort 24, 123-134.

405 Rugini, E., Silvestri, C., Ceccarelli, M., Muleo, R., Cristofori, V., 2016. Mutagenesis and 406 Biotechnology Techniques as Tools for Selecting New Stable Diploid and Tetraploid 407 Olive Genotypes and Their Dwarfing Agronomical Characterization. Hortscience 51, $408 \quad 799-804$.

409 Tous, J., Romero, A., Plana, J., 2005. Vigor. Banco de Germoplasma de Cataluña. En:

410 Variedades de olivo en España (Libro II: Variabilidad y selección). Rallo, L., Barranco, 411 D., Caballero, J.M., Del Río, C., Martín, A., Tous, J., Trujillo, I. (Eds.). Junta de 412 Andalucía, M.A.P.A. y Ediciones Mundi- Prensa. Madrid.

413 Troncoso, A., Liñán, J., Prieto, J., Cantos, M., 1990. Influence of different olive 414 rootstocks on growth and production of Gordal Sevillana. Acta Hort 286, 133-136.

415 Warschefsky, E.J., Klein, L.L., Frank, M.H., Chitwood, D.H., Londo, J.P., von Wettberg, 416 E.J.B.B., Miller, A.J., Wettberg, E.J.B. Von, Miller, A.J., 2016. Rootstocks: Diversity, 417 Domestication, and Impacts on Shoot Phenotypes. Trends Plant Sci 21, 418-437. 